\title{
A Reflection on Human Vulnerability and an Autobiographic World-View of Leadership in Human Services and, Particularly, in K-12 Schools with At-risk Students
}

\author{
Dr. Erasmus Chirume
}

Graduate Studies, College of Education, Central State University, 1400 Row Road, Wilberforce, Ohio 45384

Email: echirume@centralstate.edu

\author{
Doi:10.5901/jesr.2016.v6n2p27
}

\begin{abstract}
The achievement gap between minority students and mainstream students has generated serious concerns over the years, while a growing body of research seems to suggest that possibilities of addressing the problem, lie in leadership that teachers can provide in all schools. But the nature of leadership that teachers can practice has not always been clear, especially regarding students at risk of academic failure. In developing this phenomenological study, the researcher adopted a multi-tire research design, which triangulates analysis of data from extant literature and two vignettes to bring out the essential qualities of instructional leadership. The article concludes from the analysis that substantive school reform, comprises the reorganization of public education such that teaching and leading, embedded in the practices of (a) creativity (b) empowerment (c) acknowledgement, constitute the core functions, and the prerogative of a teacher in the classroom. The distinctive practices constitute a foundational model for understanding the emerging concept of culturally inclusive instructional leadership and atrisk students in a context of a serving relationship.
\end{abstract}

Keywords: Instructional leadership; At-risk Students; School reform, Achievement-Gap

\section{Introduction}

The nature of instructional leadership the teachers exercise, particularly regarding students at risk of academic failure in K-12, has not always been clear (Keegan \& Crescenta, 2006). While "there has never been a time in the life of the American public school when we have not known all that we needed to teach all those we chose to teach" (Edmonds 1979 , p. 3). Focused attention appears not to have been given to the investigation of the nature of instructional leadership regarding students at risk of academic failure. While the achievement gap among the demographic subgroups of K-12 remains a significant challenge, a growing body of research suggests that schools that restructure themselves as culturally inclusive learning communities, like other service based organizations, can provide high quality education that addresses student at-riskiness (Senge, 2010). The objective of this article is to contribute a leadership perspective, rooted in empowerment, creativity and acknowledgment. The aforementioned characteristics constitute active ingredients of leadership for providing learning environments marked by improved human activity, academic performance, and advancement of the wellbeing of all students. Also discussed in this paper, are the concomitant activities to be performed by instructional leaders with at-risk students. The activities include, challenging the process, encouraging the heart for others to act, and modelling the way, in a serving relationship.

\section{Statement of the Research Problem}

The "achievement gap" between minority students and mainstream students regarding the American public school system has generated serious concerns, which, over the years have resulted in a growing body of empirical research (Capper, 1993; Plucker \& Burroughs, 2010). Public attention to the phenomenon regarding the American public school system was first cited in the Coleman Report of the 1960s (Jaekyung, 2002). Since then, calls for addressing the problem of a continuing disparity in the learning outcomes of students from different ethnic and social class backgrounds have continued to be made in research circles. Goodland (1990) argues that failure to educate a group of socially disadvantaged students constitutes a national crisis that cannot be ignored in the long run. This article contributes insights about the nature of instructional leadership and at-risk students from an autobiographical examination of vignettes as well as extant literature about school reform and restructuring instructional leadership regarding at-risk students. 


\section{The Purpose of the Study}

This study proposes a model of instructional leadership for a better understanding of instructional leadership and enhancing professional practice of teachers in order to advance the wellbeing of students at risk of academic failure in $\mathrm{K}$ 12 education. The examination of the nexus of teacher leadership and student at-riskiness within the constructivist and critical theoretical paradigms, provides a refreshing epistemological perspective on improving academic achievement and overall students' wellbeing. The perspective also has a potential and, a promise for a broader impact in the expansion of social justice in the administration of public education today.

\section{Theoretical Framework}

For this article, constructivism and a critical theory are combined to provide a theoretical framework with an academic rigor appropriate for an analysis of the nexus of instructional leadership and student at-riskiness. Following, are brief expositions of each of the theoretical perspectives that constitute the theoretical framework.

\section{Constructivist Perspective on Educators and Educands}

A constructivist perspective attempts to establish whether stakeholders are empowered to share opportunities and responsibilities in utilizing the personal expertise and resources to solve challenges confronting the school and issues facing individuals (Davison \& Dell, 2003). When teachers are trusted and they discover things about students and their well-being that outsiders never would have imagined, these teachers-if they want to-can catalyze the development of their students toward future success (Block, 1993). On that note, Godwyll (2003) concluded that teachers have the potential to identify problems and can illuminate instructional areas that outside researchers would not normally identify. These observations underscore the idea that teachers occupy a unique position to deliver instructional leadership that can deeply touch the lives of their students, even those students who are at risk of academic failure.

\section{Critical Theory and the Role of Instructional Leadership}

In the troubled teaching and learning environment, educators are constantly faced with the dilemma of either remaining emotionally uninvolved or responding to their students' despondency. Watkins (1986) asserts that a critical approach to scientific inquiry on the concept of leadership focuses on the forces that underlie the processes of the construction of reality in educational organizations. According to Edmonds (1979); Mayaske, Okada, Beaton, and Wisler (1973) studies on instruction must concentrate on investigating school variables such as instructional leadership as opposed to student body variables. Studies that have dwelt on the latter variables have tended to support the status quo in education and have tended to conclude that the victim is to blame for lack of instructional improvement. Edmonds cites "The Equal Educational Opportunity Survey" conducted by Coleman and the International Association for Evaluation of Educational Achievement [which] concluded " that family background was the greatest single cause of variation in pupil performance" hence schools have insignificant influence on students' performance. However, for the purpose of instructional improvement, critical inquiry has undermined all certainties regarding the status quo of proliferating events and arrangements in today's school system by providing insight into and alternative narratives about the educational institutions.

Critical scholars such as Apple (1982), Bernstein (1990), Bourdieu (1977), Capper (1993), Foster (1986), Maxcy (1991), and Watkins (1986) emphasize the role of human agency in looking at possible ways in which members and clients behave in their organizations. In education, for example, a critical approach to inquiry offers the possibility of understanding an educational administration that helps the school community realize (i.e., human urgency) how elaborate and efficiently devised organizational plans can also create sites of exploitation and manipulation of organizational members (Watkins, 1986). Human beings form organizations to meet their social needs. However, too often those institutions distance themselves or become hostile to some of their stakeholders. That is why Apple (1982) and Bernstein (1977) argue that the main consideration of instructional leadership constitutes resolving how power penetrates educational settings and how this energy shapes the social structures that distribute and evaluate knowledge to the advantage of some but at the expense of others. 


\section{The Research Question}

What are some of the compelling attributes of culturally inclusive instructional leadership model that can be provided in the moments and spaces of teaching and learning in order to transform the performance of students at risk of academic failure in K-12schools?

\subsection{Research Design}

Kelly and Lesh (2002) suggest that the use of the term 'design' in research "allows us a broad canvas for productive thought and conversation," on the approaches of collecting and analyzing data, as well as theorizing the nexus of leadership and student at riskiness as a social phenomenon of remarkable epistemological importance (p. 2). An epistemological perspective of this phenomenological study is constructivist in nature. Constructivism blends well with the critical theory in the inquiry of the nature of leadership and at-risk students. In utilizing a multi-tire research design, this article triangulates sources of data, which in addition to extant literature include two vignettes. The first vignette provides an autobiographic worldview of leadership and a perspective on a youth's vulnerability. The second vignette, is extracted from the extant literature, while findings of a study by Chirume (2009), provide a third source of data. Thorne (2000) posits that creating a database from sources as indicated above would not be sufficient to conduct a qualitative oriented study. In order to generate findings that transform raw data into new knowledge, Thorne suggests that the researcher should engage in an active analytic process of data analysis throughout the entire research cycle, a caveat adopted in completing this study. A vignette only produces a 'snapshot' of a given situation. In response to this limitation, Finch (1987) explains that a vignette is not so much of action representation than it is emblematic of a process of meaning and understanding of data, which in fact is what substantively matters, and is of interest to the research community.

\subsubsection{Vignette l: Earlier Years}

I grew up as a first-born child of an extended family of nine children on a farm in Copper Queen, a farming district in the Southwest of Zimbabwe in Southern Africa. By the age of five, every child on the farm contributed to the family labor to ensure that multiple chores of mixed farming were completed. We all did our portion of the seasonal work, which involved herding cattle, milking cows, tilling the fields, planting seed, picking cotton, mending fences, repairing farm tools and equipment, and performing a host of other seasonal chores. On the farm, my father was the head and leader of the family. In that role he assumed sweeping powers and authority. He decided the family budget. He planned and assigned all work to be done. We each received instructions on how to execute every assignment and he assessed the performance of every member's contribution of work on the farm. Rarely did anybody receive positive feedback on what they had done. My father complained at every turn about our work. In his own judgments, the work we did, almost always turned out to be of inferior quality and or inadequate. In my case, in spite of any amount of effort I expended, he ruled that I was not making progress in any of the chores that I performed for the family. My thoughts, feelings and ideas were neither sought nor encouraged. Trapped within my frustration, moment by moment, I wondered how I could cope with the fatigue from the drearily chores of each day on the family farm and critical remarks that certainly followed each time my father assessed work I had completed. I felt alienated and became a disengaged participant. Often I slipped into daydreaming to escape from the realities of life and the drudgery of the family farm. I realized that the norms of conducting business as usual on our farm constrained overall productivity on the farm. Leadership I experienced on the family farm compromised the potential to optimize my self-worth as a human being. At the time, I attended a local primary school to which I walked forth and back to the farmhouse.

\section{Contrasting Observations in Latter Years}

At the age of 14, with little social and personal dexterity, I left the family farm and the local primary school located in the Mashonaland Region for Dadaya, a boarding high school in the Midlands Region of Zimbabwe. I remained at Dadaya High school for six years. After high school, I relocated to Harare, the capital city of Zimbabwe. As I lived in the city, during times far between, I made visits to the family farm.

During those visits, I noticed a profound transformation from the way my younger siblings, who were under the age of 14 years, interacted with my father. The leadership culture at the farm had changed from what I had known to be the case, and experienced during my childhood. This time, on typical occasions, I observed three of my youngest siblings 
and my father deliberating about the various chores that would be done on each day. The discussions were spirited. Points of view were argued out intelligently with smart decisions taken about every issue that was raised, ranging from tending cattle, tilling the land, and fixing the gate of the fence around the farm-compound, planting or harvesting crops. I was amazed and encouraged by the voices of reason, confidence, and passion of the participants engaged in their wide ranging discussions, and by the graceful manner of engagement in their work. They exchanged expressions of appreciation of each other's contribution and accomplishments on the farm. I observed that not only the culture of doing business had changed, but also productivity and general upkeep of the farm had dramatically improved, with manifestations of that positive change felt and expressed by all stakeholders in their demeanor.

In an analysis of the foregoing observations, it is noted that leadership and inclusive culture of the latter years had replaced the leadership and culture of command and control of the earlier years, much to the family's success in advancing the wellbeing every member involved in various farm enterprises. At the farm, I now witnessed stakeholder contentment comparable to that experienced by stakeholders at Beth Israel Hospital of New York in the 90s.

\subsection{Vignette II: Beth Israel Hospital}

Helgesen (1995) writes that when Joyce Clifford assumed duties as Beth Israel Hospital's director of nursing, a top-down structure common in today's public institutions was firmly in place at this hospital.

The nursing aides, who had the least preparation, had the most contact with the patients. But they had no authority of any kind. They had to go to their supervisor to ask if a patient could have an aspirin. The supervisor would then ask the head nurse who would then have to ask a doctor. The doctor would ask how long the patient had been in pain. Of course the head nurse had absolutely no idea so she had to track down, the aide to ask her, and then relay that information to the doctor. It was ridiculous... and dissatisfying situation and one in which it was impossible for the nurse to feel any satisfaction at all. The system was hierarchical fragmented, [and] impersonal (Helgesen, 1995, p.134).

In their various units, nurses were highly specialized. Some nurses were assigned to take blood pressure. Others handled medication. Still others were assigned to monitor vital illness signals. Other aides were responsible for bed making and food services. Doing business as usual at Beth Israel Hospital left an individual patient's day filled with interruptions from a multitude of virtual strangers, with none of them really knowing what was going on with the patient.

With support from her progressive Chief Executive Officer, Clifford initiated a major structural change at Beth Israel Hospital from a hierarchy with nurses at the bottom to an inclusive web with nurses at the center of care for patients. The stakeholders called the concept primary nursing, which literally became a care center. Upon admission, each primary nurse would gather information about the patient, develop a comprehensive plan that brought together a specialized team to provide a round-the-clock care to the patient, and kept the family informed about what to expect (Helgesen, 1995).

In this care center, the primary nurse became the central point of contact and information about the patient's condition. As primary nurses themselves performed a variety of tasks for a single patient, and assumed more responsibility, connections with physicians, and other hospital workers had to be revised. Instead of simply carrying out the orders of the physicians, the primary nurse became a professional partner, attending rounds and participating as an equal in treatment decisions. Business was no longer conducted as usual. Basic tasks had to be viewed differently. Rather than being viewed as an undesirable menial work, for example, bed making now was taken as an opportunity for the primary nurse to review the condition of the patient and to assess how well the treatment plan worked. Advanced technology that gave all points of the network easy access to the patient information and administrative data, enhanced Beth Israel's inclusive web of care for patients, their families, and care providers. Doing business differently advanced the quality of care for the patients and raised stakeholder satisfaction at this Hospital (Helgesen, 1995).

A constant comparative analysis of the data provided in the vignettes brings to an observation that paternalistic leadership on a family farm, or at a hospital such as Beth Israel, would be associated with drawbacks upon the human wellbeing and productivity. Similarly, a patriarchal like leadership in K-12 Education has also been associated with shortcomings rather than the expanded stakeholder wellbeing, and social justice.

\section{Critical discussion of Experiences of Teaching and Learning in Schools}

Researchers have long speculated that the achievement gap emanates from an existence of forces that cause student at-riskiness in the public school system. Goodlad (1990) writes that there are "certain institutionalized features of America's educational system that function as barriers to knowledge, especially for poor and minority students" (p. 1). 
Policy-makers create formal arrangements and services to reduce the impact of those forces on students in American classrooms, for example head start programs. However, researchers are interested in the invisible forces that public policy does not address, and yet these forces act against some, and not other students. The term "invisible forces" refers to veritable and critical forces that are not, for one reason or another, part of our "reflective awareness" (Goodlad, 1990, p. 32).

In an educational context, invisible forces lurk in the interlocking set of structural conditions found in or outside of school manifesting as curricular and instructional practices, or both, or other social and physiological conditions that block some students' access to knowledge and skills (Goodlad, 1990) or keep some students from making scholastic progress. Ladson-Billings (2000) argues that teacher preparation is culpable in the failure of teachers to teach African American students effectively. Nieto (2000) declares, "Nor are we preparing teachers to teach Hispanic students or children living in poverty, or other politically and economically disenfranchised groups" (pp. 214-215). Allen and Hermann-Wilmarh (2004) claim that because the majority of the teacher educators and teachers in the schools are essentially limited to English proficiency; they possess elaborated code and mainstream social capital, but lack the social capital and pedagogy of the marginalized. Following are some of the compelling tenets, developed from literature, in order to understand instructional leadership that teachers can practice with K-12 students.

\subsection{Interrogate the Process of Teaching and Learning and Apply Creative Solutions to the Problems}

Reflective and good K-12 teachers, who see their students struggling in economically, linguistically and culturally diverse classrooms must ask themselves what they are doing or not doing, that contributes to their students' failure to cope with educational demands. Nieto (2000) argues that educators must be willing to challenge the process, share the blame and keep placing diversity, and multicultural education "front and center" in their pedagogy to see culture, their own as well as their students' (Nieto, 2000, p. 180), as a prerequisite for culturally responsive teaching. Through creativity, this pedagogy entails recognizing and creating a space for the social capital that these students bring from their 'disadvantaged' backgrounds (Allen \& Hermann-Wilmarth, 2004, p. 214). This pedagogy entails not only allowing classrooms to be terrains for celebrating different cultures as parallel, but also acknowledging that cultures are equally complex systems of attitudes, beliefs, and norms of living and understanding the world. Failure on the part of teachers, to implicate themselves in their own narratives of teaching and their students' learning may ultimately turn out to be the genesis of an invisible force working against the marginalized students in the school environment and responsible for the national frustration about the educational systems' failure to educate all children.

\subsection{Encourage the Heart for Others to Act in an Empowering Relationship}

Human and spiritual dimensions need to play a huge part of determining the attitude and behavior of teachers (Crowther, Kaagan, Furguson, \& Hann, 2002) engendering an empowering relation with students at risk of academic failure. The emphasis must be placed on the role of values and symbols and how these can give meaning and purpose in teaching and leading. The human spirit is an inner resource that teachers draw upon to respond to "what they can obviously see in a suffering" student's eyes (Kim, 1994, p. 21). This is how teachers enact leadership regarding at-risk students, and activate and build capacity for human agency in the practice of social justice. The role of human agency in educational leadership is reflected in the constant ability of an educator or group of educators to interrogate the social structure of the educational system, and the school in particular, and to identify negative forces working against the wellbeing of some students as compared to others (Capper, 1993). Social structures of the school organization, such as rules and regulations, must not be allowed to ossify into inflexible forces that prevent or disempower teachers from helping at-risk students, or the students to respond energy and sense of purpose to instruction.

\subsection{Leadership, a Serving and Empowering Relationship}

Leadership is the human element of the school organization that creates a better learning environment in a serving relation with students. Children, families and school communities need servant leaders. Servant leaders substantively serve the best interests of diverse students and families in school communities. Bolman and Deal (1997) explain that leading, in a serving role, implies a profound and challenging responsibility for leadership to recognize and acknowledge the diversity of needs and help resolve dilemmas of students. To students at risk of academic failure, the gift of empowering servant-leaders is, love and caring. For students at risk of academic failure, love is largely absent in schools. 
Caring for students at risk of academic failure begins by knowing those who are at-risk of academic failure. This implies, listening, understanding and accepting. This occurrence progresses through a deepening sense of appreciation, respect, and ultimately love. Love is the willingness of instructional leaders to reach out to students on the axis of pain and path to academic failure. Instructional leaders do so by opening their hearts.

\subsection{Modeling the Nature of Culturally Inclusive Instructional Leadership with at-risk Students}

Modeling the way in dealing with student at-riskiness and the attendant problem of the achievement gap requires the application of the essential working parts of teacher leadership as culturally inclusive practice in the public school system. In a research about instructional leadership, Chirume (2009) observed that instructional leadership tends to be defined by teacher involvement; teacher change agency; teacher collaboration; and teacher knowledge bases for diversity.

Kim (1994) remarks that research seems to point to the fact that getting deeply involved in students' home problems is effective, "but it is draining and painful and sometimes it may seem better for everyone not to rock the boat" (p. 22). Kim (1994) admits that every situation is different, but he wonders what kind of impact or difference it would make. To this end, Frymier (1992) writes that data have shown that where those students at risk of academic failure were given instructional attention, their academic condition improved, as they felt empowered, and acknowledged. Their performance differed from that of students in a similar predicament, but were not given substantive attention. By these developments, the reader is reminded of the confidence and passion of the participants who betrothed in a wide array of activities that boosted productivity and good will generated with the help of engaged positive leadership. Kim (1994) found that sharing concerns about troubled students with colleagues, friends, and family members, in good faith (in a professional manner), does help in preventing burnout. The outcome of the collaboration of teachers, and their involvement in the lives of their students, would more than likely be empowering to the teachers themselves, and students alike.

Wassermann (1985) found that teachers, in some cases, are the only consistent people in the lives of students and, therefore, it makes perfect sense that teachers are an indispensable link to helping students at risk of academic failure. Kim writes that teachers "can actually help [students] from slipping further backwards" (p. 25). Kim (1994) found that teachers who make a difference take leadership in helping students face their problems. Those teachers who lead in their classrooms are change agents, and, according to Covey (1991), change agents improve almost any situation that they face.

Teacher collaboration is an important facet of instructional leadership. Covey (1991) observes that in team endeavors, teachers synergize with each other. Each educator overcomes and complements his or her weakness with the strengths of others. Collegiality among teachers helps each fellow member to gain a perspective on dealing with and empower troubled students (Kim, 1994). Consequently, teachers share ideas on identifying, recognizing, and accepting the troubled students' feelings. Thus, teachers find ways not to destroy, but to build up the students' sense of security and wellbeing. Crowther, Kaagan, Ferguson, and Hann (2002) insist that individuals collaborating with one another; can overcome barriers and get essential work of helping students on the path to academic failure to change, completed.

In the same way as primary care nurses themselves performed a variety of tasks for a single patient at Beth Israel Hospital, dealing with a troubled student is cited in research literature as one of the most difficult teacher leadership responsibilities. It is in this responsibility that professional development programs have the potential to make a difference in the lives of the nation's children at risk academic failure by equipping teachers with outstanding tools and disposition to make a change. Researchers found that teachers (as well as students) are socialized within cultures formed by multilayered professional communities in school districts that included minority groups. Studies have shown evidence that, professional communities with a sound mix of members from diverse cultural and socio-economic backgrounds helped members to learn from each other and cross cultural boundaries much to the advancement of the student wellbeing. These communities also enhance opportunities for teachers to improve the quality of their professional life and develop their knowledge bases for diversity and a sense of social justice.

Another important role of teacher leadership is the development of knowledge bases for diversity. Troen and Boles (2003) write that students in U.S. classrooms hail from a diverse range of cultural, national, and ethnic backgrounds. Southern Education Foundation (1996) notes that with minority students in the classrooms, training and retaining teachers who represent minority groups and the cultural differences that students bring to the classroom is an important way of addressing minority students' needs and also creating a community to share cultures in a school. In a study by Chirume (2009), $95.9 \%$ of the participants believed that educators' knowledge of the student's culture is useful for effecting instructional improvement. As teachers reflect, and dialogue with peers, they learn to take charge the 
responsibility for student learning. Whatever students learn and experience in their early years of life influences their views of who they are and their world. These experiences affect their current success (or lack of it) in school, later at work, and always in their personal lives. According Edmonds (1979) the inequalities imposed on students by their neighborhood, and their home must not be carried along to become the inequalities the students confront adult life after finishing school. The nature of instructional leadership is schematically presented in figure 1 below.

\begin{tabular}{|c|c|c|c|c|c|}
\hline DATA SOURCES & $\begin{array}{l}\text { ORGANIZATIONAL CHARACTER } \\
\text { OF LEADERHSIP }\end{array}$ & itstics & $\begin{array}{l}\text { LEADERSHIP } \\
\text { ROLE EXPECTATIONS }\end{array}$ & & $\begin{array}{c}\text { AT- RISK } \\
\text { STUDENT OUTCOMES }\end{array}$ \\
\hline Vignette 1 part 1 & $\begin{array}{l}\text { Partenalistic } \\
\text { control } \\
\text { stability } \\
\text { Predictability }\end{array}$ & & $\begin{array}{l}\text { Don't rock the boat } \\
\text { Maintenance of status quo }\end{array}$ & - & $\begin{array}{l}\text { Decline of student } \\
\text { well-being }\end{array}$ \\
\hline $\begin{array}{l}\text { Vignette 1 partz } \\
\text { Vignette Z } \\
\text { Extant Literature }\end{array}$ & $\begin{array}{l}\text { Distributed leadership } \\
\text { Creativity } \\
\text { Acknowledgment } \\
\text { Empowerment }\end{array}$ & 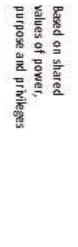 & $\begin{array}{l}\text { Challenge the process } \\
\text { Encourage the heart for others to act } \\
\text { Leadership, a serving rel ationship } \\
\text { Modelling the way } \\
\text { Teacherinvolment } \\
\text { Teacher Collaboration } \\
\text { Teacher Human Agency } \\
\text { Knowledge bases for diversity }\end{array}$ & 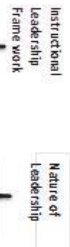 & $\rightarrow \mid \begin{array}{l}\text { Increase in student } \\
\text { well-being }\end{array}$ \\
\hline
\end{tabular}

Figure 1: Autobiographical worldview of instructional leadership view and student wellbeing

As the demographics of the United States as a whole, become more diverse, matching and complementing the skills of teachers of minority and dominant backgrounds, as well as underrepresented groups in all institutions and at all levels of society so as to reflect the national, racial texture in the population, can help address students,' and the nation's needs for the twenty-first century human development. A diverse teaching force will create favorable conditions for optimizing teacher involvement, teacher collaboration, and human agency which all is necessary to advance student wellbeing in the public school system.

\section{Conclusion}

A comparative analysis of the data provided in the vignettes brings to a conclusion that paternalistic leadership that advances the norms of control, command for predictability and stability either on a family farm, or at a hospital such as Beth Israel, would be associated with drawbacks upon the human wellbeing and productivity. Similarly, a patriarchal leadership form in K-12 Education has also been associated with shortcomings rather than pervasive stakeholder wellbeing, and expansion of social justice in schools. Better school environments are created as culturally inclusive environments. In these environments, teachers as leaders, engage in furthering human needs, goals, and opportunities for all students, by employing a leadership model which is rooted in the values of (a) creativity in problem solving activities, (b) empowerment of all social actors in the school organization, and (c) acknowledgement of individual and group synergy of strengths and resources. Therefore, school reform from this view, requires that the public education system should be reorganized. Teaching and leading, through the model of creativity, empowerment and acknowledgement as core functions of instructional leadership, ought to become the teacher's prerogative in the classroom so as to facilitate learning, meet the standards, and advance the wellbeing of all K-12 students.

\section{References}

Allen, J., \& Hermann-Wilmarth, J. (2004). Cultural construction zones. Journal of Teacher Education, 55 (3), 214-226.

Apple, M. W. (1982). Education and power. Boston: Routledge \& Kegan Paul.

Bernstein, B. (1990). The structuring of pedagogic discourse: Class, codes and control (vol. 4). London, New York: Routledge.

Block, P. (1993). Stewardship: Choosing service over self- interest. San Francisco, CA: Berrett-Koehler Publishers Inc.

Bolman, L.G., Deal, T. E. (1997). Reframing Organizations, Artistry, Choice, and Leadership. San Fransico, Jossey Bass Publishers.

Bourdieu, P. (1977). Outline of a theory of practice. Cambridge: Cambridge University Press.

Capper, C. A. (Ed). (1993). Educational administration in a pluralistic society. New York: State University of New York Press

Chirume, E. L. (2009). A study of educational leadership: Principals' and teachers' perceptions of teacher leadership dynamics in Southeast Ohio. VDM Verlag. 
Covey, S. R. (1991). Principle-centered leadership. New York: Summit Books.

Crowther, F., Kaagan, S. S., Furguson, M., \& Hann, L. (2002). Developing teacher Leaders: How teacher leadership enhances school success. California: Corwin Press, Inc.

Davidson, B. M., \& Dell, G. L. (2003, April). A school restructuring model: A tool kit for building teacher leadership. Paper presented at the annual meeting of the American Educational Research Association, Chicago, IL.

Edmonds, R.R., (1979). A discussion of the literature and issues related to effective schooling. 49pp. (Eric Document 170394 )

Finch, J. (1987). The Vignette technique in survey research, Sociology, 21, 105-11

Foster, W. (1986). Paradigms and promises: New approaches to educational administration. New York: Prometheus Books.

Frymier, J. (1992). Children who hurt, children who fail. Phi Delta Kappan, 74(3), 257-279.

Godwyll, E. F. (2003). Development and evaluation of diagnostically supported teaching strategies to reduce school failure in Ghana. Retrieved August 22, 2005, from http://www.ub.uni-heidelberg.de/archiv/3645

Goodlad, J. I., \& Keating, P. (1990). Access to knowledge: An agenda for our nation's schools. New York: College Entrance Examination Board.

Helgesen, S. The Web of Inclusion: A new architecture for building great organizations. New York: Currency/Double Day, 1995

Jaekyung, L. (2002). Racial and ethnic achievement gap trends: Reversing the progress toward equity? Educational Researcher, 31(1), 3-12.

Keegan, R. W., \& Crescenta, L. (2006, April 17). Arnold sells his road to success. Time, 167(16), 37.

Kelly, A. E. and Lesh, R. (2002). Hand-book of research design in mathematics and science teaching, Mahwah NJ: Lawrence Erlbaum.

Kim, S. (1994). Attitudes of involvement with students' problems outside of school. US Department of Education: The Educational Resources Information Center.

Kohl, H. (1994). "I won't learn from you" and other thoughts on creative maladjustment. New York: New Press.

Ladson-Billings, G. (2000). Fighting for our lives: Preparing teachers to teach African American students. Journal of Teacher Education, 51(3) 206- 214.

Maxcy, S. J. (1991). Educational leadership: A critical pragmatic perspective. New York: Greenwood Publishing Group Inc.

Mayeske, G. W., Okada, T., Beaton, A.E. and Wisler, C.E. (1973). A Study of the Achievement of our Nation's Students. Office of Education (DHEW), Washington, D.C.

Nieto, S. (2000). Placing equity front and center: some thoughts on transforming teacher education for a new century. Journal of Teacher Education, 51(3), 180- 187.

Plucker, J. A., Burroughs, .,R. (2011) Mind the (other gap! The growing excellence gap in -12 education.Bloomington, N; Center for Evaluation and Policy.

Senge, P. (2010). Schools that learn: A Fifth Discipline field book for educators, parents and everyone who cares about education. New York: Double day.

Troen, V., \& Boles, K. C. (2003). Who's teaching your children?: Why the teacher crises is worse than you think and what can be done about it. New Haven, CT: Yale University Press.

Wassermann, S. (1985). Even teachers get the blues: Helping teachers to help kids to learn. Childhood Education, 62, 3-7.

Watkins, P. E. (1986). Critical review, leadership concepts research: Implications, Educational Administration. Victoria: Deakin University. 